\title{
Landscape Metrics: Past Progress and Future Directions
}

\author{
Amy E. Frazier ${ }^{1} \cdot$ Peter Kedron $^{1}$
}

Published online: 5 August 2017

(C) Springer International Publishing AG 2017

\begin{abstract}
Purpose of the Review This paper reviews progress in the field of landscape ecology related to the development of landscape metrics (i.e., spatial pattern indices). We first review the major formative historical developments that contributed to the coalescence of landscape metrics as a sub-field of landscape ecology and then examine recent literature highlighting several shortcomings related to their utility for understanding ecological processes and discuss several alternative approaches.

Recent Findings Recent research recognizes some limitations of the patch-mosaic model (PMM), including the landscape metrics based on it, for capturing landscape heterogeneity and measuring functionality. Collapsing land cover information into nominal classes complicates identification of ecologically meaningful relationships and effective management. We explore several alternative methods for capturing landscape functionality and spatial heterogeneity including graph-based networks and gradient surface models with associated surface metrics.

Summary With complementary patch-based, gradient, and graph network models available, the goal for landscape ecologists is to select the correct approach, or combination of approaches, for investigating the issue at hand. Biases associated with the modifiable areal unit problem (MAUP) and its connection to heterogeneity and scale-both grain and
\end{abstract}

This article is part of the Topical Collection on Methodological Development

Amy E. Frazier

amy.e.frazier@okstate.edu

1 Department of Geography, Oklahoma State University, 337 Murray Hall, Stillwater, OK 74078, USA extent-complicate these decisions, but empirical tools from spatial allometry may improve the ability for landscape ecologists to assess where metrics are capturing ecological processes versus the scale-dependency of the metrics themselves.

Keywords Landscape structure - Composition · Configuration · Scaling · Patch mosaic $\cdot$ Gradient surface, graph theory

\section{Introduction}

From its nascent beginnings at the Allerton Park meeting in 1983, landscape ecology differentiated itself from traditional ecology through its explicit focus on spatial pattern [1]. While the discipline has expanded and evolved considerably over the past three decades, the central aim of landscape ecological theory has remained virtually unchanged - to elucidate the impact of landscape structure, which emerges from the composition and configuration of landscape features, on ecological processes $[2,3]$. In the years following Allerton Park, landscape ecologists dedicated considerable efforts toward measuring the relationships between pattern and process by developing methods and tools to quantify landscape structure [4-7]. These early efforts were bolstered by rapidly improving computational power throughout the 1980s and 1990s [8] along with development of geographic information systems (GIS), ultimately coalescing in a comprehensive set of landscape metrics and software programs (e.g., FRAGSTATS; [9]) for completing spatial pattern analyses.

The ability to quantify spatial patterns in a computationally efficient manner fostered unprecedented developments in landscape ecological theory and practice during those early decades [10], ultimately sparking the emergence of a subfield of landscape ecology focused on metrics $[3,11]$. The 
intellectual energy surrounding spatial pattern analysis helped landscape ecology bring spatial analysis and modeling to the forefront of ecological research in the 1980s [12] and solidified the field's core focus. Progress continues today with development of new and improved indices for quantifying composition and configuration [13], ongoing research into the parsimonious selection of metrics for ecological analyses [14], and renewed investigations into enduring issues of uncertainty and error propagation $[15,16]$. Alongside these lasting topics, new research themes are emerging to create new insights into the prediction power of landscape metrics through scaling functions $[17,18]$ and, most recently, into the innovative application of entropy and thermodynamics [19]. Landscape ecology's vibrant development and diverse disciplinary perspectives continue to infiltrate diverse fields such as urban and regional studies [20, 21], economics [22], and social and environmental perception [23-25] through metric analyses.

Currently, hundreds of metrics exist to measure landscape patterns across a multitude of applications, but their use is not without scrutiny. For decades, researchers have debated the ecological relevancy of spatial patterns [3••, 26, 27], with some casting doubt on their ability to measure the functionality of a landscape adequately [28]. Contributing to these uncertainties, the scale dependency of many metrics across both grain (i.e., resolution) and study area extent confounds relationships between ecological processes and spatial patterns, making management decisions based on single-scale data difficult, and possibly erroneous. Underlying these issues remains the simple fact that conventional landscape metrics are built on the patch-mosaic model (PMM), which simplifies landscapes into a mosaic of discrete patches that may not adequately capture ecological heterogeneity [29]. While the PMM has helped advance our understanding of patternprocess relationships [11] and fostered contributions to ecological theory, recent conceptual and methodological developments have created an impetus to explore other options. One stream within the literature advocates conceptualizing the landscape as an environmental gradient [29-34], the patterns of which can be quantified through alternate surface metrics that measure heterogeneity in gradient datasets [35]. However, this gradient surface model (GSM) is not without critique. To date, many of the issues hampering the PMM also remain unexplored within the GSM, such as the ecological relevancy of metrics, thus limiting applications.

In this review, we examine recent landscape ecology research exploring the development, implementation, and use of spatial pattern metrics for both basic (theoretical) and applied science. First, we briefly summarize several major historical developments contributing to the coalescence of landscape metrics as the backbone of spatial pattern analysis in landscape ecology. Next, we examine recent literature on landscape metrics and highlight some of the recognized shortcomings of the utility of these patch-based metrics for understanding ecological processes. We then explore several alternative approaches for quantifying landscape patterns including graph-based methods and GSMs. Lastly, we discuss some future directions for spatial pattern metrics in landscape ecology that take advantage of their scale dependencies. Throughout the paper we use the term spatial pattern metrics to refer to all quantitative measurements of heterogeneity regardless of the landscape model (i.e., PMM or GSM). We refer specifically to metrics computed for categorical, patchbased landscapes as 'landscape metrics' or 'conventional landscape metrics', and we refer to metrics computed on gradient surfaces as 'surface metrics' while also recognizing that certain autocorrelation measures (e.g., Moran's I) would fall into this category as well. The terms 'metrics' and 'indices' are used interchangeably.

\section{A Brief History of Trends and Development}

Development of landscape metrics was occurring long before landscape ecology officially coalesced as a field of study in North America. Citing Aldo Leopold's law of interspersion [36], Patton [37] developed what is widely recognized as one of the first landscape metrics: a diversity index to quantify 'edge'. Patton's efforts sparked further index development throughout the 1980s [38-40], and in 1988, O'Neill et al. [5] published their seminal paper "Indices of landscape pattern", which developed three new metrics based on information theory and fractal geometry. This paper remains the top-cited article published in the journal Landscape Ecology. Subsequent efforts improved and refined the existing suite of metrics to better capture heterogeneity through new measures of fragmentation [41], aggregation [42], and connectivity (see [43] for a review), as well as specific measures for interspersion and juxtaposition [44], and patch cohesion [45], among others. Today, the development of new and improved metrics remains a productive stream of research that shows few signs of abating $[13,20]$.

Persistent efforts to develop new metrics derive, at least in part, from the tailoring of early metrics to specific applications, which limited the array of metrics originally offered [44]. Despite O'Neill et al.'s [5] central argument that a small set of metrics is adequate to capture significant aspects of landscape pattern, researchers continued to generate new metrics. The growing number of available indices created new challenges for landscape ecologists in the form of correlation and redundancy. Researchers responded by focusing investigations on selecting parsimonious sets of metrics using established methods such as factor analysis [46], classification trees [8], and principal components analysis (PCA) [47, 48]. Advances in this realm have led to increased sensitivity analyses in recent years to improve landscape metric selection 
[49-51] and identify consistent patterns across both spatial scale and time $[52,53]$. Related research has focused on fostering consistency across studies through shared databases [54] and identifying core sets of metrics for applications such as biodiversity $[55,56]$.

As focus was expanding from how to best measure landscape patterns to explicit examination of the metrics themselves, researchers began recognizing that the data used to compute landscape metrics (e.g., land cover maps derived from remotely sensed imagery) were not always accurate. In 2002, Wu and Hobbs ([10], 355) listed "data acquisition and accuracy assessment" among the top ten research priorities in landscape ecology, prompting theoretical discussions surrounding the proper use (and misuse) of landscape metrics [12]. Similarly, Iverson [57] stressed that adequate data with known accuracy were critical for advancing landscape ecology. In response, investigations into the impacts of mapping error on landscape metrics grew, with studies specifically examining how the errors inherent in land cover classifications are propagated into landscape pattern analyses [58-61]. Perhaps most importantly though, these discussions sparked broader recognition that landscape metric behavior can change according to data quality, classification error, and scale, including both grain and study area extent. The lack of foundational understanding of the behavior of landscape metrics and their interwoven relationships with the abovementioned factors complicates their contribution to the central question of how landscape structure impacts ecological processes $[62,63]$. Thus, linking landscape metrics with ecological processes was outlined as a key research priority for landscape ecologists nearly 15 years ago [10] and remains an essential focus of current and future research [64, 65].

\section{Some Limitations of Conventional Landscape Metrics}

Landscape ecology was codified under the assumption that spatial patterns influence ecological processes [27], and landscape metrics were quickly adopted as the primary vehicle for elucidating these relationships [6, 66]. Kupfer [3] recently observed though that widespread assumptions that metrics "capture functional landscape properties is perhaps too universally accepted, and the ecological relevance of many landscape indices is often unproven and questionable." ([3], 5). Kupfer [3] is not the first to recognize this drawback as other researchers have questioned whether landscape metrics are appropriate for explaining ecological processes [12, 26-28, 67]. In their widely-cited paper 'Use and misuse of landscape indices', $\mathrm{Li}$ and $\mathrm{Wu}[12]$ point to three contributing factors to explain why landscape metrics have failed to meet our expectations of improving our understanding of ecological processes: (1) conceptual flaws in the analysis such as unwarranted relationships between pattern and process or ecological irrelevance of landscape metrics, (2) the inherent limitations of metrics such as their variable responses to spatial pattern changes, and (3) improper application or use of metrics such as quantifying pattern absent a consideration of the underlying process. These factors can result in difficulties interpreting index values and inappropriate inferences, ultimately leading to ecological irrelevancy.

More recently, researchers have pointed to other reasons for the uncertainties surrounding the applicability of landscape metrics: mainly, they typically do not account for the variation in ecological response variables when used as a proxy for landscape structure [48, 68, 69•]. Specifically, Uuemaa et al. [48] found that a large component of the variation of ecological response variable(s) is only moderately well-explained with landscape metrics when using correlation analysis. Where studies have been successful at uncovering relationships between spatial patterns and ecological processes [66], the relationships are often not statistically significant and have limited explanatory power, thus, they may not provide any real causal understanding of the underlying ecological mechanisms [12, 69•].

Selecting metrics that include a functional component, such as core area, may help in better linking landscape structure and ecological function [3]. Functional metrics explicitly measure how the landscape functions for a particular organism or phenomenon under investigation, and studies have had success using this approach [70]. However, functional metrics require additional, organism-specific information that is not always easy to obtain. Syrbe and Walz [71] assessed landscape functionality in terms of ecosystem services using metrics but caution that landscape metrics should only be used in situations where the ecosystem service in question has a strong structural component. By determining the underlying processes of each ecosystem service, a decision can be made regarding whether or not an appropriate structural metric exists that is appropriate for linking pattern and process.

Complications associated with extracting meaningful, realworld explanations of ecological processes from landscape metrics are, in part, due to the underlying nature of the PMM. The development, use, and application of metrics has rested almost entirely on conceptualizing the landscape as a mosaic of discrete patches, and there has been near-uniformity in adoption of this model across landscape ecology [35]. Indeed, common usage of the term "landscape metrics" has come to refer exclusively to indices computed for categorical map patterns [48]. Aggregating data into areal units is necessary to represent real-world phenomena, but the process can introduce statistical biases known as the modifiable areal unit problem [72], or MAUP. Problems stemming from these biases are familiar across the sciences for their role in contributing to ecological fallacies, and the PMM is fraught with MAUP biases. First, the pixel-based classifications on which 
patch-mosaics are often built collapse intra-pixel heterogeneity into a single, areal unit. Second, when maps are aggregated to coarser resolutions, often through majority rules aggregation, the already-collapsed heterogeneity in single pixels is collapsed even further into larger pixels. While the PMM is lauded for its conceptual simplicity and the ease with which categorical land cover maps can be analyzed using conventional landscape metrics, it presents a very limited view of underlying reality [69•]. Metrics and indices built and applied on this foundation may be inconsistent with ecological theory since they ignore the continuous gradient nature of environments [29]. Consequently, they may inhibit our ability to derive universal insights into pattern-process relationships [69•]. Overcoming the loss of heterogeneity that occurs during aggregation of pixel-based land cover maps requires alternative solutions and leveraging of cross-disciplinary strengths.

\section{Alternative Approaches}

To better link landscape pattern and function, researchers use graph theoretical approaches including networks and circuitry [3]. Graph-based approaches represent the landscape using nodes (i.e., patches) connected through edges that join together pairs of nodes according to their functionality (e.g., dispersal routes) [73]. While the unit of analysis for graph-based approaches is still discrete patches, nodes can incorporate both qualitative and quantitative information, and edges can incorporate weights or directions, allowing graphs to better represent the relationships between landscape structure and function [74]. For example, Ferrari et al. [75] show how peaks in graph diameter, which represent the distance an organism would have to traverse to cross the largest inter-patch cluster, can be used to predict ecological thresholds for management of functional fragmentation.

The incorporation of graph-based methods opens landscape ecology to conceptual approaches emerging elsewhere within the geographical sciences. For instance, in regional studies and economic geography, non-geographic conceptualizations of 'distance' such as social network characteristics or technological similarity are often used to define graph edges $[76,77]$. Landscape ecologists may profit from capturing functional landscape connectivity in similar, non-Euclidean/ non-geodesic manners. A graph-based landscape could weight edges between patch nodes by, for example, genetic similarities of the particular species under investigation, species richness and abundance measures, variations in management practices, or multi-dimensional composites of these and other ecologically relevant factors.

Since graph theory has enjoyed a long history of exploration and development, there are numerous tools and algorithms available, many of which have been developed into software programs specifically suited for landscape analyses (e.g., Conefor Sensinode [78] and LANDGRAPHS [79]). The ease and availability of software has led to a myriad of global and local graph-based network indices for landscape ecologists (see [80] for a review). However, these network indices suffer from similar redundancy and correlation issues as patch-mosaic landscape metrics, but, following examples from the patch-mosaic realm (e.g., [46, 47]), recent work [80] has begun to weigh in on their parsimonious selection. Also, while graph approaches may better capture landscape functionality through measures of node connectivity and centrality [3], and there is increasing use and acceptance of graph theoretical approaches in landscape ecology [81], it is important to remember that graphs are constrained by how nodes and links are defined [82, 83]. Zetterberg et al. [84] provide one framework for operationalizing graph theory for landscape ecological investigations, but many basic research questions in this area remain far from settled.

Moving beyond the PMM, gradient approaches have been promoted in ecology since Gleason [85] questioned whether categorical vegetation typologies were consistent with real world heterogeneity. Gradients have been proposed and debated as an alternative way of conceptualizing and representing landscape structure for decades [29-34]. In 2002, when Wu and Hobbs ([10], 355) advised "relating landscape metrics to ecological processes" as a key research agenda item for landscape ecology, they prudently accompanied this challenge with advice for landscape ecologists to "go beyond" patch-based landscape metrics and incorporate other forms of heterogeneity. Researchers responded by developing representations of the landscape where pixels are not confined to a single land cover class but instead take on ratio values representing the proportion of a land cover (or other variable) present in a pixel (Fig. 1). These gradient datasets capture and represent more of the heterogeneity present in real-world landscapes compared to patch-mosaic models $[35,86]$ and can be derived from categorical maps by statistically combining data (i.e., through moving windows). They can also be created directly from remote sensing imagery through spectral unmixing $[18,87]$ or computation of vegetation indices such as the normalized difference vegetation index $[29,88]$.

A dilemma (or opportunity, depending on perspective) for landscape ecologists is that gradient surfaces do not have discrete boundaries and therefore cannot be analyzed using conventional landscape metrics and software packages [87]. A new form of metrics - surface metrics - has been introduced for landscape ecologists to quantify heterogeneity of continuous gradient surfaces [35]. Surface metrics are founded on methods for quantifying three-dimensional surfaces from microscopy and molecular physics [89], and have recently been adapted for landscape analyses $[35,90]$. They may hold potential for advancing landscape ecological theory by overcoming the inconsistencies that exist between real-world landscapes and the patch-mosaic model (see Fig. 1) and 
a) NAIP Imagery $(1 \mathrm{~m})$

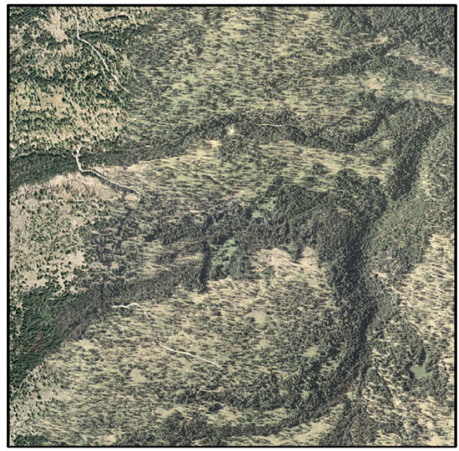

Red Band

Green Band

Blue Band b) Patch-mosaic land cover (30m)

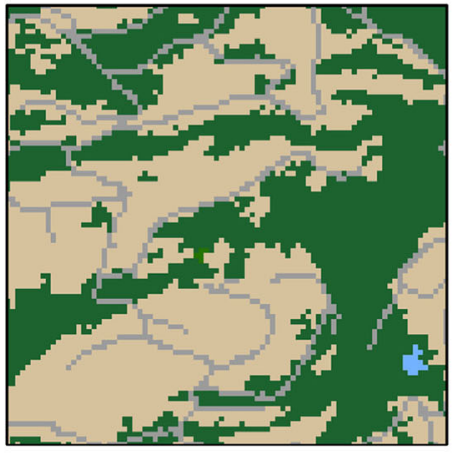

Roads

Forest

Rangeland

Water c) Gradient tree cover (30m)

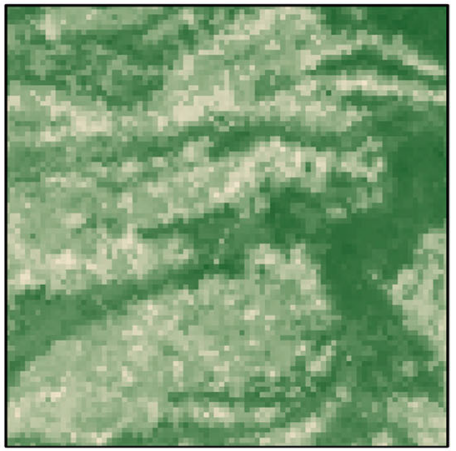

High : $100 \%$

Low : $0 \%$
Fig. 1 Comparison of $\mathbf{a}$ a high resolution aerial photo with $\mathbf{b}$ a patchmosaic model of land cover and $\mathbf{c}$ a gradient surface model of tree canopy cover for a forested landscape. Data sources: a National Agricultural

transforming how we conceptualize, quantify, and analyze the relationships between heterogeneity and ecological processes. Surface metrics have been applied in several ecological contexts [91-93], but, as with other methods discussed in this paper, their use is not without limitations.

Surface metrics were developed in mechanical engineering and manufacturing to identify ideal bearing surfaces, defined as being "smooth with relatively deep scratches to hold and distribute lubricant" ([94], 1). This concept does not translate flawlessly into ecology, and interpretation of surface metrics is not always intuitive from a landscape perspective. Additionally, many surface metrics rely on the Abbott-Firestone Bearing Area Curve, so there are similar correlation and redundancy issues as with conventional landscape metrics and graph approaches. Widespread adoption of surface metrics has been hindered by limited access to software (although surface metrics are anticipated in a forthcoming version of FRAGSTATS [9]), which has further slowed theory development, methodological refinement, and empirical validation. Yet, it is important to remember that conventional landscape metrics have benefitted from more than 30 years of research and development, and alternative approaches will require comparable levels of attention and maturation if they are to have similar impacts on the field.

In summary, there are many approaches for quantifying spatial patterns in landscapes, and there is no "one fits all" solution. All three of the approaches discussed (conventional landscape metrics, graph theoretical methods, and surface metrics) suffer from correlation and redundancy issues. Like many other aspects of ecology, the linkages between pattern and process within all three approaches also depend on the scale of the data (both grain and extent) [95], the unit of analysis (i.e., how patches are defined) (e.g., [96]), and the relevancy of these data with respect to the problem being considered. Often, the data used in landscape
Imagery Program, $\boldsymbol{b}$ National Land Cover Database, $\boldsymbol{c}$ Tree Canopy Cover product. Both $\boldsymbol{b}$ and $\boldsymbol{c}$ produced by the Multi-Resolution Land Characteristics Consortium (MRLC) ecological investigations are acquired via satellite imagery or other means that reflect anthropogenic views of the landscape and thus may not be appropriate for many ecological phenomena [8]. Thus, the goal for landscape ecologists is to find the correct approach for investigating the issue at hand, which may include a combination of methods. Studies have combined graph networks with patch-based landscape conceptualizations to analyze forest connectivity [78, 97], but integrated approaches using gradient landscapes are still developing. Alternatively, by segmenting a gradient surface at various thresholds (e.g., [88]), it is possible to define non-uniform, heterogeneous patches of a land cover. These patches can be assigned node weights in a graph model based on their composition, and edge weights can be assigned according to Euclidean distance, geodesic distance, or any of the alternate proximity measures discussed previously. Such blended approaches simultaneously capture structural characteristics of the total landscape while also representing important habitat relationships of ecological relevance.

\section{Future Directions}

Despite the numerous contributions that advances in spatial pattern analysis have made to landscape ecology and related fields, overcoming MAUP biases rooted in heterogeneity and scale remains a central challenge. Without the interrelated effects of heterogeneity and scale, landscapes would be uniform, thus negating the need for spatial pattern analyses. However, landscapes are spatially heterogeneous, and any inferences about an ecological system through either conventional, patch-based landscape metrics, graph network approaches, or surface metrics are dependent on that heterogeneity and its relationship with the scale (i.e., grain and/or extent) of the investigation [98]. For this reason, 
multiscale investigations are common throughout landscape ecology where general allometric equations are often applied to plots of metric values against spatial scale, including both grain and study area extent [99]. Researchers have begun testing whether observed landscape patterns across scales are simply manifestations of the basic scale-dependency of metrics, or whether there may be intrinsic characteristics of the landscape patterns being captured $[15,100,101 \bullet]$. Using such approaches, studies have revealed consistent and robust scaling relationships for certain spatial pattern metrics across both resolution or extent (see [102] for a review). However, multiscale investigations of spatial pattern metrics have only begun to advance past describing the variations of different landscape metrics with scale [103].

Spatial allometry provides a valuable empirical method for not only summarizing observations across scales but also extrapolating patterns to predict measurements at unsampled

(a) Patch-mosaic land cover

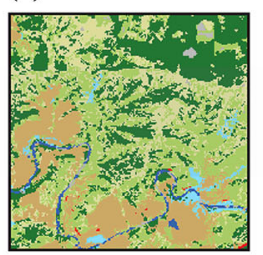

$30 \mathrm{~m}$

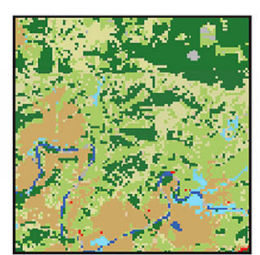

$90 \mathrm{~m}$

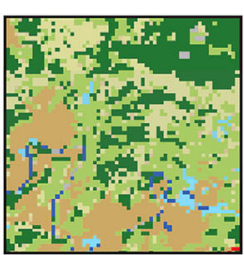

$150 \mathrm{~m}$

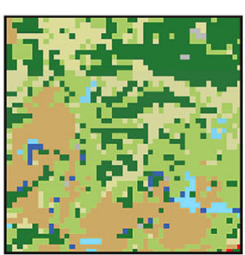

$210 \mathrm{~m}$

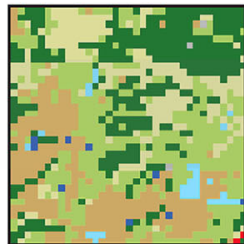

$270 \mathrm{~m}$

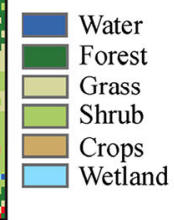

(b) Gradient tree canopy cover

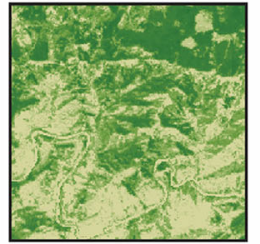

$30 \mathrm{~m}$

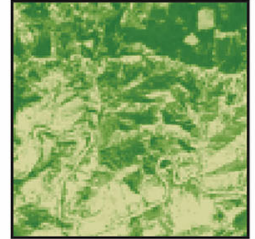

$90 \mathrm{~m}$

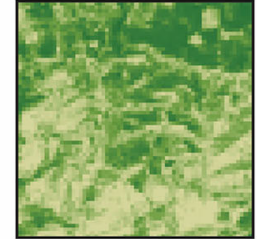

$150 \mathrm{~m}$

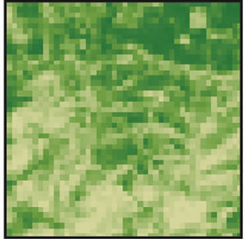

$210 \mathrm{~m}$

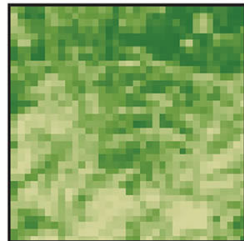

$270 \mathrm{~m}$

Canopy Cover

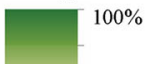

$-0 \%$

Patch-mosaic landscape metrics

(c) Patch Density (PD)

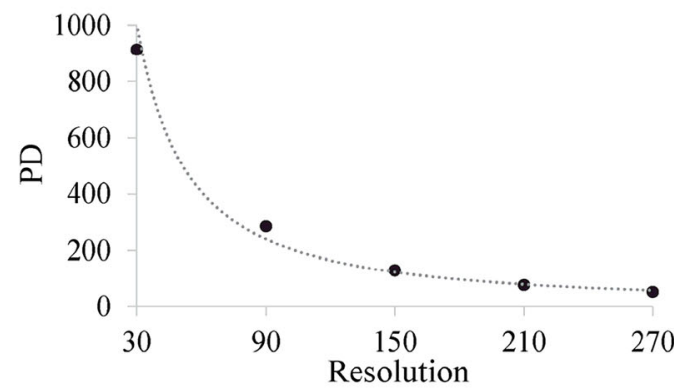

(e) Perimeter-Area Factal Dimension (PAFRAC)

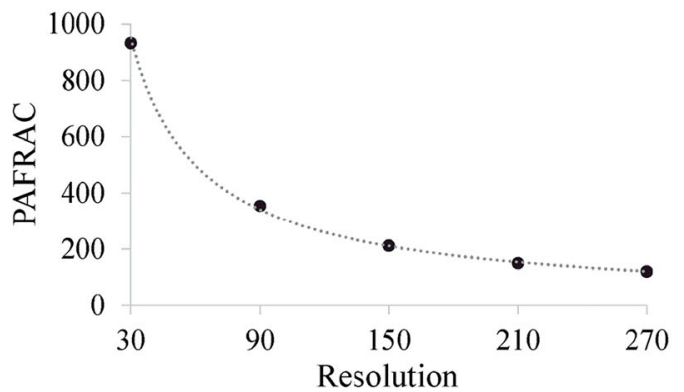

Fig. 2 Aggregated data for a a patch-mosaic land cover model with a category for forest (dark green pixels) and $\mathbf{b}$ a gradient surface model of the same area showing percent canopy cover (high percentages in darker green). Associated graphs show the similarities and dissimilarities of the (d) Peak Density (Sds)

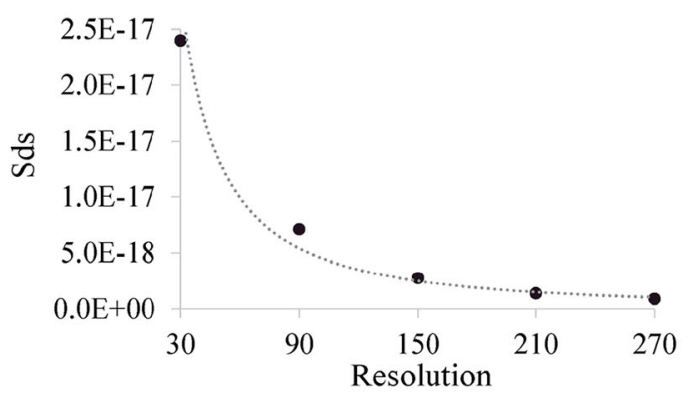

(f) Surface Fractal Dimension (Sfd)

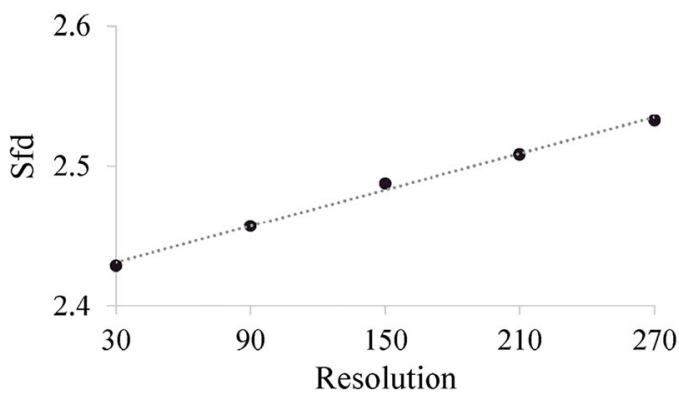

scaling functions for analogous metrics in the patch and surface paradigm for the forest class and percent canopy cover, respectively: $\mathbf{c}$ patch density and its gradient analog $\mathbf{d}$ peak density, and e perimeter-area fractal dimension and its gradient analog $\mathbf{f}$ surface fractal dimension 
scales [99, 104, 105]. Successful extrapolation would enable spatial pattern metrics to be generated at scales matching the intrinsic scale of the underlying ecological process even if data sources are not directly available at that scale [7, 106]. Researchers have tested the power of conventional landscape metric scaling functions to predict metrics at finer grain sizes through a variety of downscaling methods [17, 18, 106-109]. However, the general consensus has been that prediction power is poor, with the loss of heterogeneity during grain size transformation (e.g., majority rules aggregation) cited as a major factor inhibiting progress $[18,91]$. As such, researchers have struggled to operationalize the information in scaling functions for meaningful exploration of cross-scale issues.

Capturing additional heterogeneity through gradient surfaces may allow researchers to better extrapolate spatial allometric equations to make accurate predictions of spatial patterns across grain sizes/resolutions. The ratio data in surfaces can be statistically transformed using, for example, mean values instead of majority rules so less information is lost during aggregation. Surface metrics have also been found to exhibit consistent and robust scaling relationships across resolutions, much like their patch-mosaic counterparts, but with improvements in downscaling accuracy [91]. Generating accurate representations of the landscape at each scale translates into scaling functions that are more precise and can thus be extrapolated for prediction. One promising avenue for improving extrapolation is to consider local scaling relationships across scale domains, which are portions of the scale spectrum in which pattern-process relationships are consistent [98]. Scaling functions fit across domain transitions may better capture how changes in heterogeneity impact spatial patterns. However, additional research is needed into the scaling relationships of surface metrics across different spatial extents.

Regardless of the data model (i.e., PMM or GSM), researchers must still determine whether observed relationships are capturing the characteristics of the landscape patterns or are simply manifestations of the basic scale-dependency of the metrics themselves [ 15 , $100,101 \bullet]$. To illustrate this point, two sets of patch-based landscape metrics and their analogous gradient surface metrics [35] are plotted against map resolution (Fig. 2). Patch density (PD) measures the number of patches per area (Fig. 2c) for patch-mosaic landscapes while peak density (Sds) is an analogous surface metric that measures the number of local peaks per area (Fig. 2d). As resolution changes, these two metrics show almost identical scaling functions across the two paradigms, even though they were computed using different datasets. Conversely, the graphs for perimeterarea fractal dimension (PAFRAC), which measures fractal dimension for patch-mosaics (Fig. 2e), and its analog in the surface paradigm, surface fractal dimension (Sfd) (Fig. 2f), show different scaling relationships (power law versus linear). At present, we remain uncertain whether these differences in relationship correspondence between the scaling relationship of analagous metrics are simply a manifestation of scale dependencies of the metrics or differences in how surface and patch metrics capture landscape structure. More research is needed to understand how re-scaling data introduces systematic biases into scaling relationships and how we might differentiate those relationships driven solely by scale dependencies versus those that are driven by landscape structure. Tools that are applicable across ecoregions and land cover types will help contribute to landscape ecological investigations as well as theoretical developments for understanding and overcoming MAUP.

In summary, heterogeneity and scale are central to the analysis of landscape patterns yet continue to confound our understanding of pattern-process relationships in landscape ecology due to MAUP biases. Untangling the interdependencies of heterogeneity and scale remain a great research challenge for the future, because these interdependencies can lead a researcher to misattribute the effects of landscape pattern characteristics to artifacts from the metrics, and vice versa. Consideration of scale and scaling can assist landscape ecologists tasked with finding the best approach for investigating the ecological issue at hand.

\section{Conclusions}

Landscape metrics have provided a backbone for spatial pattern analysis in landscape ecology for more than three decades during which they have fostered unprecedented developments in ecological theory and practice. Concomitant with these accomplishments, landscape metrics have sometimes been scrutinized for several shortcomings related to their utility for understanding ecological processes including the MAUP biases associated with the patchmosaic model, which collapses spatial heterogeneity - the foundation of landscape ecology — into discrete units and thus presents a very limited view of the underlying reality. We presented several alternative methods for capturing landscape functionality and spatial heterogeneity including graph-based networks and gradient surface models along with associated surface metrics while recognizing that the goal for landscape ecologists is to select the correct approach, or combination of approaches, for investigating the issue at hand. Moving forward, multiscale investigations across patchmosaic, gradient, and graph network models can advance past simply describing variations of metrics with scale and move toward exploiting scaling relationships for identifying pattern-process relationships.

Acknowledgements This work was funded, in part, by a grant to the authors from the National Science Foundation (\#SBE-1561021).

\section{Compliance with Ethical Standards}

Conflict of Interest On behalf of all authors, the corresponding author states that there is no conflict of interest.

Human and Animal Rights and Informed Consent On behalf of all authors, the corresponding author confirms that this article does not contain any studies with human or animal subjects performed by any of the authors. 


\section{References}

Papers of particular interest, published recently, have been highlighted as:

- Of importance

- Of major importance

1. Risser PG, Karr JR. Forman RTT. Landscape ecology: directions and approaches. Illinois Natural History Survey Special Publication Number 2;1984.

2. Kupfer JA, Theory in landscape ecology and its relevance to biogeography. The SAGE handbook of biogeography. Thousand Oaks: Sage;2011. p. 57.

3. Kupfer JA Landscape ecology and biogeography: rethinking landscape metrics in a post-FRAGSTATS landscape. Prog Phys Geogr. 2012. doi:10.1177/0309133312439594.

4. Li H, Reynolds JF. A new contagion index to quantify spatial patterns of landscapes. Landsc Ecol. 1993;8(3):155-62.

5. O'Neill RV, et al. Indices of landscape pattern. Landsc Ecol. 1988;1(3): 10

6. Turner MG. Spatial and temporal analysis of landscape patterns. Landsc Ecol. 1990;4(1):21-30.

7. Turner MG, Gardner RH. Quantitative methods in landscape ecology. New York: Springer; 1991.

8. Lausch A, Herzog F. Applicability of landscape metrics for the monitoring of landscape change: issues of scale, resolution and interpretability. Ecol Indic. 2002;2(1):3-15.

9. McGarigal K, Cushman SA, Ene E. FRAGSTATS v4: spatial pattern analysis program for categorical and continuous maps. Computer software program produced by the authors at the University of Massachusetts, Amherst; 2012. Available at: http:// www.umass.edu/landeco/research/fragstats/fragstats.html.

10. Wu J, Hobbs R. Key issues and research priorities in landscape ecology: an idiosyncratic synthesis. Landsc Ecol. 2002;17(4): 355-65.

11. Turner MG. Landscape ecology: what is the state of the science? Annu Rev Ecol Evol Syst. 2005;36:319-44.

12. $\mathrm{Li} \mathrm{H}, \mathrm{Wu}$ J. Use and misuse of landscape indices. Landsc Ecol. 2004;19(4):389-99.

13. Li W, et al. NMMI: a mass compactness measure for spatial pattern analysis of areal features. Ann Assoc Am Geogr. 2014;104(6):1116-33.

14. Schindler S, et al. Performance of methods to select landscape metrics for modelling species richness. Ecol Model. 2015;295: 107-12.

15. Lechner AM, et al. Are landscape ecologists addressing uncertainty in their remote sensing data? Landsc Ecol. 2012;27(9):124961.

16. Parent JR, Volin JC. Validating Landsat-based landscape metrics with fine-grained land cover data. Ecol Indic. 2016;60:668-77.

17. Argañaraz JP, Entraigas I. Scaling functions evaluation for estimation of landscape metrics at higher resolutions. Eco Inform. 2014;22:1-12.

18. Frazier AE. A new data aggregation technique to improve landscape metric downscaling. Landsc Ecol. 2014;29(7):1261-76.

19. Cushman SA. Calculating the configurational entropy of a landscape mosaic. Landsc Ecol. 2016;31(3):481-9.

20. Li W, Goodchild MF, Church R. An efficient measure of compactness for two-dimensional shapes and its application in regionalization problems. Int J Geogr Inf Sci. 2013;27(6):1227-50.

21. Zhou W, Huang G, Cadenasso ML. Does spatial configuration matter? Understanding the effects of land cover pattern on land surface temperature in urban landscapes. Landsc Urban Plan. 2011;102(1):54-63.
22. Nunes PA and Loureiro ML. Economic valuation of climatechange-induced vinery landscape impacts on tourism flows in Tuscany. Agric Econ. 2016;47:365-374. doi:10.1111/agec.12236

23. Brown GG, Reed P. Social landscape metrics: measures for understanding place values from public participation geographic information systems (PPGIS). Landsc Res. 2012;37(1):73-90.

24. De Vreese R, et al. Social mapping of perceived ecosystem services supply-the role of social landscape metrics and social hotspots for integrated ecosystem services assessment, landscape planning and management. Ecol Indic. 2016;66:517-33.

25. Llausàs $\mathrm{A}$, Nogué $\mathrm{J}$. Indicators of landscape fragmentation: the case for combining ecological indices and the perceptive approach. Ecol Indic. 2012;15(1):85-91.

26. Gustafson EJ. Quantifying landscape spatial pattern: what is the state of the art? Ecosystems. 1998;1(2):143-56.

27. Turner MG. Landscape ecology: the effect of pattern on process. Annu Rev Ecol Syst. 1989;20:171-97.

28. Dramstad WE. Spatial metrics-useful indicators for society or mainly fun tools for landscape ecologists? Norsk Geogr TidsskrNor J Geogr. 2009;63(4):246-54.

29. Cushman SA, et al.. The gradient paradigm: a conceptual and analytical framework for landscape ecology, in Spatial complexity, informatics, and wildlife conservation. Heidelberg: Springer; 2010. p. 83-108.

30. Manning AD, Lindenmayer DB, Nix HA. Continua and Umwelt: novel perspectives on viewing landscapes. Oikos. 2004;104(3): 621-8.

31. McIntyre S, Hobbs R. A framework for conceptualizing human effects on landscapes and its relevance to management and research models. Conserv Biol. 1999;13(6):1282-92.

32. Evans JS, Cushman SA. Gradient modeling of conifer species using random forests. Landsc Ecol. 2009;24(5):673-83.

33. McGarigal K and Cushman SA. The gradient concept of landscape structure. In: Issues and perspectives in landscape ecology. Cambridge University Press; 2005. p. 112-9.

34. McIntyre S, Barrett G. Habitat variegation, an alternative to fragmentation. Conserv Biol. 1992;6(1):146-7.

35. McGarigal K, Tagil S, Cushman SA. Surface metrics: an alternative to patch metrics for the quantification of landscape structure. Landsc Ecol. 2009;24(3):433-50.

36. Leopold A. Game and wild life conservation. Condor. 1932;34(2): 103-6.

37. Patton DR. A diversity index for quantifying habitat "edge". Wil Soc Bull (1973-2006). 1975;3(4):171-3.

38. Brooks RT, Scott CT. Quantifying land-use edge from aerial photographs. Wildl Soc Bull (1973-2006). 1983;11(4):389-91.

39. Brunt JW, Conley W. Behavior of a multivariate algorithm for ecological edge detection. Ecol Model. 1990;49(3-4):179-203.

40. Gates JE, Mosher JA. A functional approach to estimating habitat edge width for birds. Am Midl Nat. 1981;105(1):189-92.

41. Jaeger JA. Landscape division, splitting index, and effective mesh size: new measures of landscape fragmentation. Landsc Ecol. 2000;15(2):115-30.

42. He HS, DeZonia BE, Mladenoff DJ. An aggregation index (AI) to quantify spatial patterns of landscapes. Landsc Ecol. 2000;15(7): 591-601.

43. Kindlmann P, Burel F. Connectivity measures: a review. Landsc Ecol. 2008;23(8):879-90.

44. McGarigal K and Marks BJ. Spatial pattern analysis program for quantifying landscape structure. Gen. Tech. Rep. PNW-GTR-351. US Department of Agriculture, Forest Service, Pacific Northwest Research Station; 1995.

45. Schumaker NH. Using landscape indices to predict habitat connectivity. Ecology. 1996;77(4):1210-25.

46. Riitters $\mathrm{KH}$, et al. A factor analysis of landscape pattern and structure metrics. Landsc Ecol. 1995;10(1):23-39. 
47. Cushman SA, McGarigal K, Neel MC. Parsimony in landscape metrics: strength, universality, and consistency. Ecol Indic. 2008;8(5):691-703.

48. Uuemaa E, et al. Analysing the spatial structure of the Estonian landscapes: which landscape metrics are the most suitable for comparing different landscapes? Estonian J Ecol. 2011;60(1): $70 œ 80$.

49. Liu Y, et al. Sensitivity of correlation structure of class-and landscape-level metrics in three diverse regions. Ecol Indic. 2016;64: 9-19.

50. Pasher J, et al. Optimizing landscape selection for estimating relative effects of landscape variables on ecological responses. Landsc Ecol. 2013;28(3):371-83.

51. Szabó S, Túri Z, Márton S. Factors biasing the correlation structure of patch level landscape metrics. Ecol Indic. 2014;36:1-10.

52. Kelly M, Tuxen KA, Stralberg D. Mapping changes to vegetation pattern in a restoring wetland: finding pattern metrics that are consistent across spatial scale and time. Ecol Indic. 2011;11(2): 263-73.

53. Plexida SG, et al. Selecting landscape metrics as indicators of spatial heterogeneity - a comparison among Greek landscapes. Int J Appl Earth Obs Geoinf. 2014;26:26-35.

54. Pfeifer $\mathrm{M}$, et al. BIOFRAG-a new database for analyzing BIOdiversity responses to forest FRAGmentation. Ecol Evol. 2014;4(9):1524-37.

55. Schindler S, Poirazidis K, Wrbka T. Towards a core set of landscape metrics for biodiversity assessments: a case study from Dadia National Park, Greece. Ecol Indic. 2008;8(5):502-14.

56. Walz U. Landscape structure, landscape metrics and biodiversity. Living Rev Landsc Res. 2011;5(3):1-35.

57. Iverson LR. Adequate data of known accuracy are critical to advancing the field of landscape ecology. In: Wu J, Hobbs R (eds.) Key topics in landscape ecology. Cambridge University Press; 2007. p. 11-38.

58. Burnicki AC. Impact of error on landscape pattern analyses performed on land-cover change maps. Landsc Ecol. 2012;27(5): 713-29.

59. Fang $\mathrm{S}$, et al. The impact of misclassification in land use maps in the prediction of landscape dynamics. Landsc Ecol. 2006;21(2): $233-42$.

60. Huang C, Geiger E, Kupfer J. Sensitivity of landscape metrics to classification scheme. Int J Remote Sens. 2006;27(14):2927-48.

61. Shao $\mathrm{G}, \mathrm{Wu}$ J. On the accuracy of landscape pattern analysis using remote sensing data. Landsc Ecol. 2008;23(5):505-11.

62. Hargis CD, Bissonette JA, David JL. The behavior of landscape metrics commonly used in the study of habitat fragmentation. Landsc Ecol. 1998;13(3):167-86.

63. Neel MC, McGarigal K, Cushman SA. Behavior of class-level landscape metrics across gradients of class aggregation and area. Landsc Ecol. 2004;19(4):435-55.

64. Hansson L, Fahrig L, and Merriam G. Mosaic landscapes and ecological processes. Berlin: Springer; 2012.

65. Wu J. Key concepts and research topics in landscape ecology revisited: 30 years after the Allerton Park workshop. Landsc Ecol. 2013;28(1):1-11.

66. Uuemaa E, Mander Ü, Marja R. Trends in the use of landscape spatial metrics as landscape indicators: a review. Ecol Indic. 2013;28:100-6.

67. Tischendorf L. Can landscape indices predict ecological processes consistently? Landsc Ecol. 2001;16(3):235-54.

68. Dale VH, Kline KL. Issues in using landscape indicators to assess land changes. Ecol Indic. 2013;28:91-9.

69. Lausch A, et al. Understanding and quantifying landscape structure-a review on relevant process characteristics, data models and landscape metrics. Ecol Model. 2015;295:31-41. This review compares the patch-mosaic and gradient surface models in terms of their prospects for quantifying the effects of landscape structure on ecological processes along with the drawbacks of each model. It represents a key step toward determining if new insights can be derived from continuous landscape representations.

70. Walz U, Syrbe R-U. Linking landscape structure and biodiversity. Ecol Indic. 2013;31(8):1-5.

71. Syrbe R-U, Walz U. Spatial indicators for the assessment of ecosystem services: providing, benefiting and connecting areas and landscape metrics. Ecol Indic. 2012;21:80-8.

72. Openshaw S, Taylor PJ. A million or so correlation coefficients: three experiments on the modifiable areal unit problem. Stat Appl Spat Sci. 1979;21:127-44.

73. Urban D, Keitt T. Landscape connectivity: a graph-theoretic perspective. Ecology. 2001;82(5):1205-18.

74. Dale M, Fortin M. From graphs to spatial graphs. Annu Rev Ecol Evol Syst. 2010;41:21-38.

75. Ferrari JR, Lookingbill TR, Neel MC. Two measures of landscape-graph connectivity: assessment across gradients in area and configuration. Landsc Ecol. 2007;22(9):1315-23.

76. Frenken K, Van Oort F, Verburg T. Related variety, unrelated variety and regional economic growth. Reg Stud. 2007;41(5):68597.

77. Kogler DF, Rigby DL, Tucker I. Mapping knowledge space and technological relatedness in US cities. Eur Plan Stud. 2013;21(9): 1374-91.

78. Saura S, Torne J. Conefor Sensinode 2.2: a software package for quantifying the importance of habitat patches for landscape connectivity. Environ Model Softw. 2009;24(1):135-9.

79. Urban D. LANDGRAPHS: a package for graph theoretic analyses of landscapes. Durham: Landscape Ecology Laboratory, Duke University; 2003.

80. Baranyi G, et al. Contribution of habitat patches to network connectivity: redundancy and uniqueness of topological indices. Ecol Indic. 2011;11(5):1301-10.

81. Luque S, Saura S, Fortin M-J. Landscape connectivity analysis for conservation: insights from combining new methods with ecological and genetic data. Landsc Ecol. 2012;27(2):153-7.

82. Moilanen A. On the limitations of graph-theoretic connectivity in spatial ecology and conservation. J Appl Ecol. 2011;48(6):15437.

83. Rayfield B, Fortin M-J, Fall A. Connectivity for conservation: a framework to classify network measures. Ecology. 2011;92(4): 847-58.

84. Zetterberg A, Mörtberg UM, Balfors B. Making graph theory operational for landscape ecological assessments, planning, and design. Landsc Urban Plan. 2010;95(4):181-91.

85. Gleason HA. The individualistic concept of the plant association. Bull Torrey Bot Club. 1926; p. 7-26.

86. Frazier AE. Landscape heterogeneity and scale considerations for super-resolution mapping. Int J Remote Sens. 2015;36(9):2395408.

87. Frazier A, Wang L. Characterizing spatial patterns of invasive species using sub-pixel classifications. Remote Sens Environ. 2011;115(8):1997-2007.

88. Frazier AE, Wang L. Modeling landscape structure response across a gradient of land cover intensity. Landsc Ecol. 2013;28(2):233-46.

89. Stout K, et al.. The development of methods for the characterization of surface roughness on three dimensions. Pulication no EUR 15178 Commission of the European Communities; 1994.

90. Gadelmawla E, et al. Roughness parameters. J Mater Process Technol. 2002;123(1):133-45.

91. Frazier AE. Surface metrics: scaling relationships and downscaling behavior. Landsc Ecol. 2016;31(2):351-63. 
92. Moniem HEMA, Holland JD. Habitat connectivity for pollinator beetles using surface metrics. Landsc Ecol. 2013;28(7):1251-67.

93. Scown MW, Thoms MC, De Jager NR. Measuring floodplain spatial patterns using continuous surface metrics at multiple scales. Geomorphology. 2015;245:87-101.

94. Stewart M. A new approach to the use of bearing area curve. Soc Manuf Eng; 1990.

95. Schindler S, et al. Multiscale performance of landscape metrics as indicators of species richness of plants, insects and vertebrates. Ecol Indic. 2013;31:41-8.

96. Bruton MJ, et al. Testing the relevance of binary, mosaic and continuous landscape conceptualisations to reptiles in regenerating dryland landscapes. Landsc Ecol. 2015;30(4):715-28.

97. Saura S, et al. Key structural forest connectors can be identified by combining landscape spatial pattern and network analyses. For Ecol Manag. 2011;262(2):150-60.

98. Wiens JA. Spatial scaling in ecology. Funct Ecol. 1989;3(4):385-97.

99. Wu J, Li H. Perspectives and methods of scaling. In: Scaling and uncertainty analysis in ecology. Heidelberg: Springer; 2006, p. $17-44$.

100. Estreguil C, De Rigo D, Caudullo G. A proposal for an integrated modelling framework to characterise habitat pattern. Environ Model Softw. 2014;52:176-91.

101. Lustig A, et al. Towards more predictable and consistent landscape metrics across spatial scales. Ecol Indic. 2015;57:11-21. An investigation into the relationship between intrinsic characteristics of spatial patterns and extrinsic scale-dependent factors impacting characterization of landscape patterns that highlights their complex interactions.

102. Símová $\mathrm{P}$, Gdulová K. Landscape indices behavior: a review of scale effects. Appl Geogr. 2012;34:385-94.

103. Pascual-Hortal L, Saura S. Impact of spatial scale on the identification of critical habitat patches for the maintenance of landscape connectivity. Landsc Urban Plan. 2007;83(2):176-86.

104. Wu J. Effects of changing scale on landscape pattern analysis: scaling relations. Landsc Ecol. 2004;19(2):125-38.

105. Wu J. Scale and scaling: a cross-disciplinary perspective. In: Wu J, Hobbs R (eds.) Key topics in landscape ecology. Cambridge University Press; 2007. p. 115-142.

106. Saura S, Castro S. Scaling functions for landscape pattern metrics derived from remotely sensed data: are their subpixel estimates really accurate? ISPRS J Photogramm Remote Sens. 2007;62(3): 201-16.

107. Mander Ü, Müller F, Wrbka T. Functional and structural landscape indicators: upscaling and downscaling problems. Ecol Indic. 2005;5(4):267-72.

108. Riitters KH. Downscaling indicators of forest habitat structure from national assessments. Ecol Indic. 2005;5(4):273-9.

109. Shen $\mathrm{W}$, et al. Evaluating empirical scaling relations of pattern metrics with simulated landscapes. Ecography. 2004;27(4):459-69. 